$\begin{array}{ll} & \text { Etnográfica } \\ \text { etnográfica } & \text { Revista do Centro em Rede de Investigação em }\end{array}$

Antropologia

vol. 21 (3) | 2017

Vol. 21 (3)

\title{
Festivais de cultura popular e patrimônios: campos de batalhas nas políticas de identidades
}

Folk culture festivals and heritage: battle arenas in identity politics

\section{Patricia Silva Osorio}

\section{OpenEdition}

Journals

Edição electrónica

URL: https://journals.openedition.org/etnografica/4995

DOI: 10.4000/etnografica.4995

ISSN: 2182-2891

\section{Editora}

Centro em Rede de Investigação em Antropologia

\section{Edição impressa}

Data de publição: 1 outubro 2017

Paginação: 493-508

ISSN: 0873-6561

\section{Refêrencia eletrónica}

Patricia Silva Osorio, «Festivais de cultura popular e patrimônios: campos de batalhas nas políticas de identidades», Etnográfica [Online], vol. 21 (3) | 2017, posto online no dia 22 março 2018, consultado o 10 fevereiro 2022. URL: http://journals.openedition.org/etnografica/4995 ; DOI: https://doi.org/ 10.4000/etnografica.4995

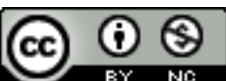

Etnográfica is licensed under a Creative Commons Attribution-NonCommercial 4.0 International License. 


\section{Festivais de cultura popular e patrimônios: campos de batalhas nas políticas de identidades}

\section{Patricia Silva Osorio}

A atualidade dos estudos sobre festa na antropologia esboça-se em um quadro teórico que sublinha as múltiplas interações sociais quando da ampliação dos cenários e contextos festivos. Associada ao turismo, ao espetáculo, ao mercado ou aos "patrimônios", a festa põe em ação e tensão zonas discursivas conflitantes e paradoxais. Conflitos políticos, reivindicações identitárias e disputas por poder e reconhecimento são algumas das batalhas travadas na arena festiva. A partir de uma etnografia realizada entre os anos de 2009 e 2014 no Festival de Cururu e Siriri em Cuiabá (Mato Grosso, Brasil), o artigo pretende problematizar contextos em que expressões da cultura popular são atravessadas pelas políticas patrimoniais. As políticas patrimoniais propiciam visibilidade e reconhecimento público, fornecem referências e criam consensos, ao mesmo tempo em que intensificam uma série de disputas associadas às reivindicações identitárias.

PALAVRAS-CHAVE: festival, cultura popular, patrimônio, políticas de identidades.

Folk culture festivals and heritage: battle arenas in identity politics - Present studies of festivities in anthropology are developed in a theoretical framework that emphasizes the multiple social interactions in expanding festive contexts and scenarios. Associated with tourism, spectacle, the market and "heritage," festivities set in motion conflicting and paradoxical discursive zones. Political conflicts, identity claims and power and recognition disputes are some of the battles fought in the festive arena. Based on an ethnography carried out between 2009 and 2014 at the Cururu and Siriri Festival in Cuiabá (Mato Grosso, Brazil), this article aims to inquire into contexts in which expressions of popular culture are crossed by patrimonial policies. The latter offer visibility and public recognition, provide references and create consensus, while at the same time intensify different disputes associated with identity claims.

KEYWORDS: festival, popular culture, heritage, identity politics.

OSORIO, Patricia Silva (patricia.osorio@gmail.com) - Departamento de Antropologia, programa de pós-graduação em Antropologia Social e programa de pós-graduação em Estudos de Cultura Contemporânea, Universidade Federal de Mato Grosso, Brasil. 
OS ESTUDOS SOBRE AS FESTAS NÃO SÃO NOVIDADE NA ANTROPOLOGIA. ${ }^{1}$ Autores clássicos da teoria antropológica chamam atenção para a importância dos eventos comemorativos. Emile Durkheim, em As Formas Elementares da Vida Religiosa, livro publicado em 1912-1913, percebe os eventos festivos não apenas como representações e expressões de ideias, mas antes de tudo como ações (Durkheim 1996 [1912-13]). São momentos de reunião nos quais a "sociedade se faz", sente sua existência enquanto tal, e é por meio dessa ação comum que a vida coletiva se afirma, se refaz e se atualiza.

Pensadas como rituais, as festas expõem a dimensão simbólica da vida humana. Com o foco no poder metafórico e complexo do aparato ritual, o estudo de recursos expressivos como as festas coloca-se como uma via de acesso aos modos como entendimentos e experiências comuns podem ser gerados (Turner 2013). Pesquisas etnográficas apontam para as festas como veículos para a erupção de sociabilidades, modos específicos de apropriação do espaço, conceptualização do tempo e vínculos de pertencimentos (Velasco 1982; Leal 1994; Cavalcanti 1994).

A atualidade dos estudos sobre a festa esboça-se em um quadro teórico que sublinha as múltiplas interações sociais quando da ampliação dos cenários e contextos festivos. Como exemplo, refiro as pesquisas sobre os chamados festivais folclóricos ou de cultura popular. A incidência destes eventos festivos, destinados a um grande público, é problematizada com reflexões sobre processos de espetacularização, turistificação, objetificação, mercantilização e patrimonialização da cultura (Boissevain 1992; Gutiérrez e Fabre 1995; Guss 2000a; Picard e Robinson 2009; Picard 2016). Sob diferentes perspectivas teóricas e universos etnográficos, os estudos mostram que os festivais não são meros reflexos, mas engendram e fornecem respostas ao turismo, ao mercado e às políticas patrimoniais.

Associada ao turismo, ao espetáculo, ao mercado ou aos "patrimônios", a festa põe em ação e tensão zonas discursivas e textualizações conflitantes e paradoxais. Conflitos políticos, reivindicações identitárias e disputas por poder e reconhecimento são algumas das batalhas travadas na arena festiva. Ao refletir sobre as políticas de identidades esboçadas em eventos festivos, o artigo objetiva problematizar o vínculo entre festivais de cultura popular e patrimônios imateriais. A preocupação central é a de refletir sobre a ampliação dos cenários festivos associados a grupos de cultura popular e atravessados por políticas patrimoniais.

A reflexão aqui construída pauta-se na etnografia, pensada enquanto um instrumento metodológico, mas também como um instrumento intelectual

$1 \quad$ Este artigo resulta do projeto de pesquisa de pós-doutorado "Expressões da cultura popular na contemporaneidade: o caso do siriri mato-grossense”, que beneficiou de uma bolsa da Capes para estágio sênior no exterior, no período de fevereiro a agosto de 2015. O estágio foi realizado no CRIA/ISCTE-IUL, com supervisão de Paulo Raposo. 
que pressupõe o esforço para a "descrição densa" (Geertz 1989). A discussão será construída a partir de um caso etnográfico, o do Festival de Cururu e Siriri, realizado anualmente em Cuiabá (Mato Grosso, Brasil). Investigar os modos como as formas expressivas populares se atualizam no contexto dos grandes festivais implica em alguns desafios metodológicos relacionados à ampliação do que se "observa". A etnografia foi realizada entre os anos de 2009 e 2014 e em dois momentos diferenciados: durante a festa, com dados coletados entre as arquibancadas, palcos, bastidores, público e os executores das performances; e antes/após a festa, nos ensaios que antecedem o festival e por meio de entrevistas com integrantes dos grupos e representantes de instituições envolvidas na organização do evento festivo.

\section{A EMERGÊNCIA DOS FESTIVAIS E DOS PATRIMÔNIOS}

O siriri e o cururu são duas expressões que envolvem música e dança, comuns no estado de Mato Grosso, região Centro-Oeste do Brasil (figura 1). Mato Grosso é a terceira unidade federativa do Brasil em área territorial, e suas fronteiras se estendem a seis estados brasileiros (Amazonas, Pará, Tocantins, Goiás, Rondônia, Mato Grosso do Sul), e ao país vizinho, a Bolívia. ${ }^{2}$ Atualmente é

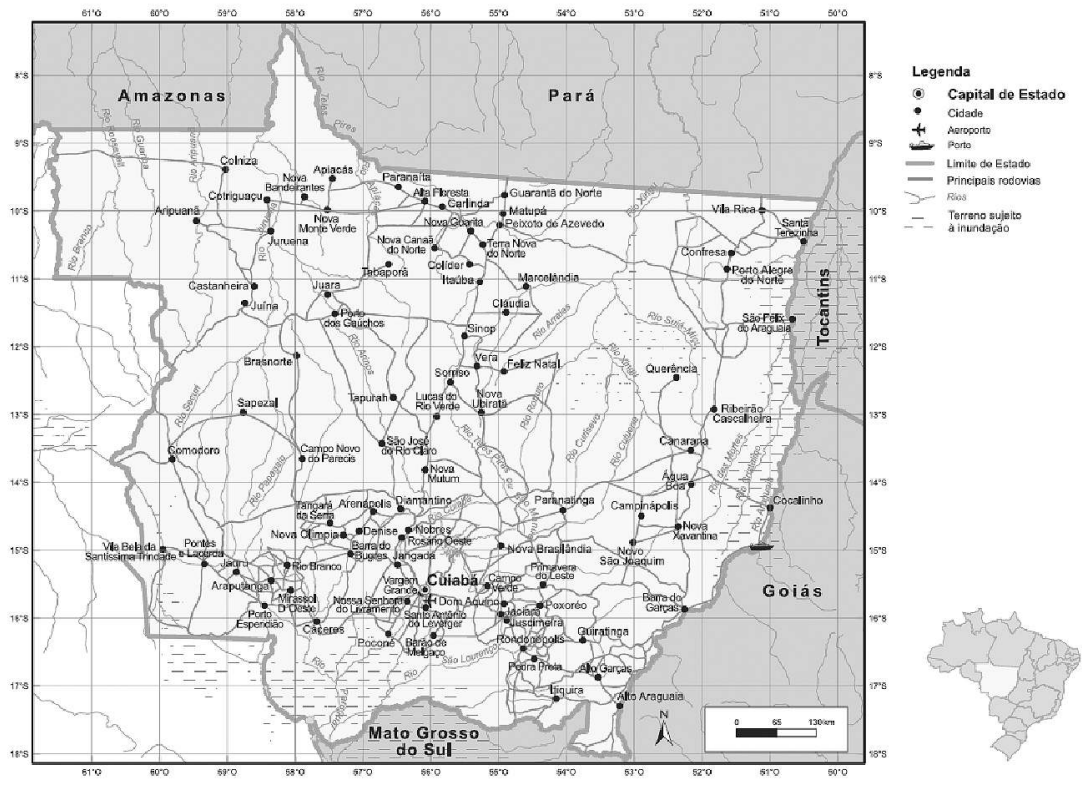

Figura 1 - Mapa de Mato Grosso e suas fronteiras. Fonte: IBGE (2012).

2 O estado tem 903.378,292 km², segundo dados do Instituto Brasileiro de Geografia e Estatística (IBGE 2017). 
reconhecido como o estado do agrobusiness, com destaque na produção de soja, algodão, milho e cana de açúcar, além de ter o maior rebanho bovino de corte do Brasil. Ao lado da grande exploração agropecuária está sua biodiversidade, representada por três biomas: a Amazônia, o cerrado e o pantanal, este reconhecido como Patrimônio Natural da Humanidade pela Unesco em 2001.

O cenário é rico no que se refere à diversidade de formas expressivas das culturas populares. Algumas delas presentes em outras localidades do país, como o congo e a folia de reis, outras mais restritas à região mato-grossense, como o siriri e o cururu. Estas expressões preenchem o cenário das festas realizadas em comemoração de santos católicos e para o pagamento de promessas.

O cururu é executado apenas por homens que dançam em roda e emitem versos de improviso ao som de um instrumento de corda, a viola de cocho, e de um instrumento percussivo, o ganzá, enquanto que o siriri é dançado por homens e mulheres que aos pares executam coreografias em rodas ou fileiras ao som da viola de cocho, ganzá e mocho (este último uma espécie de tambor, repercutido com duas baquetas). O cururu tem protagonismo no momento mais solene da festa, dedicado às rezas e às procissões, em que os homens dançam e tocam diante de um altar. O siriri é o momento do baile, da descontração e do divertimento (figuras 2 e 3 ).

Atualmente os cenários de exibição ampliam-se para além das festas de santo. Um caso exemplar é o surgimento em Cuiabá do Festival de Cururu e Siriri no início dos anos 2000 e que mobiliza grupos de diferentes cidades de Mato Grosso. O público é composto por turistas de passagem pela região, mas

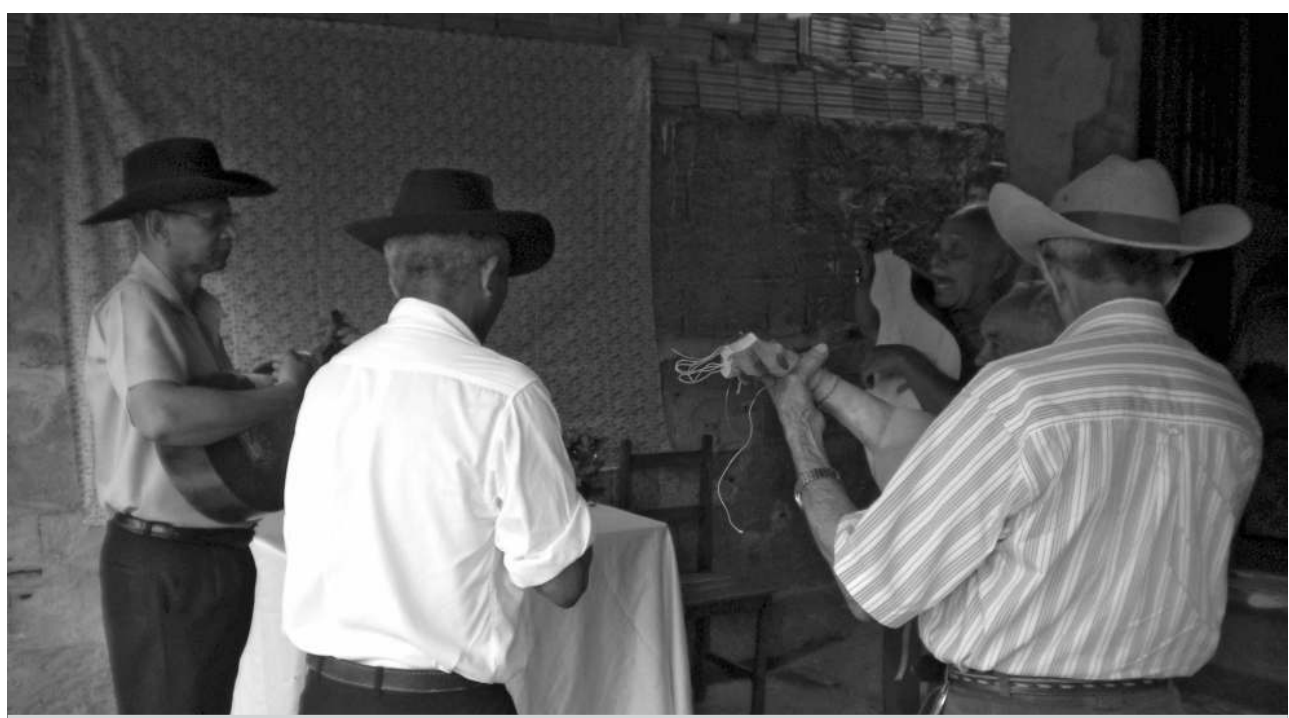

Figura 2 - Roda de cururu em uma festa de santo, Cuiabá (MT). Foto: Patricia Osorio, 2012. 


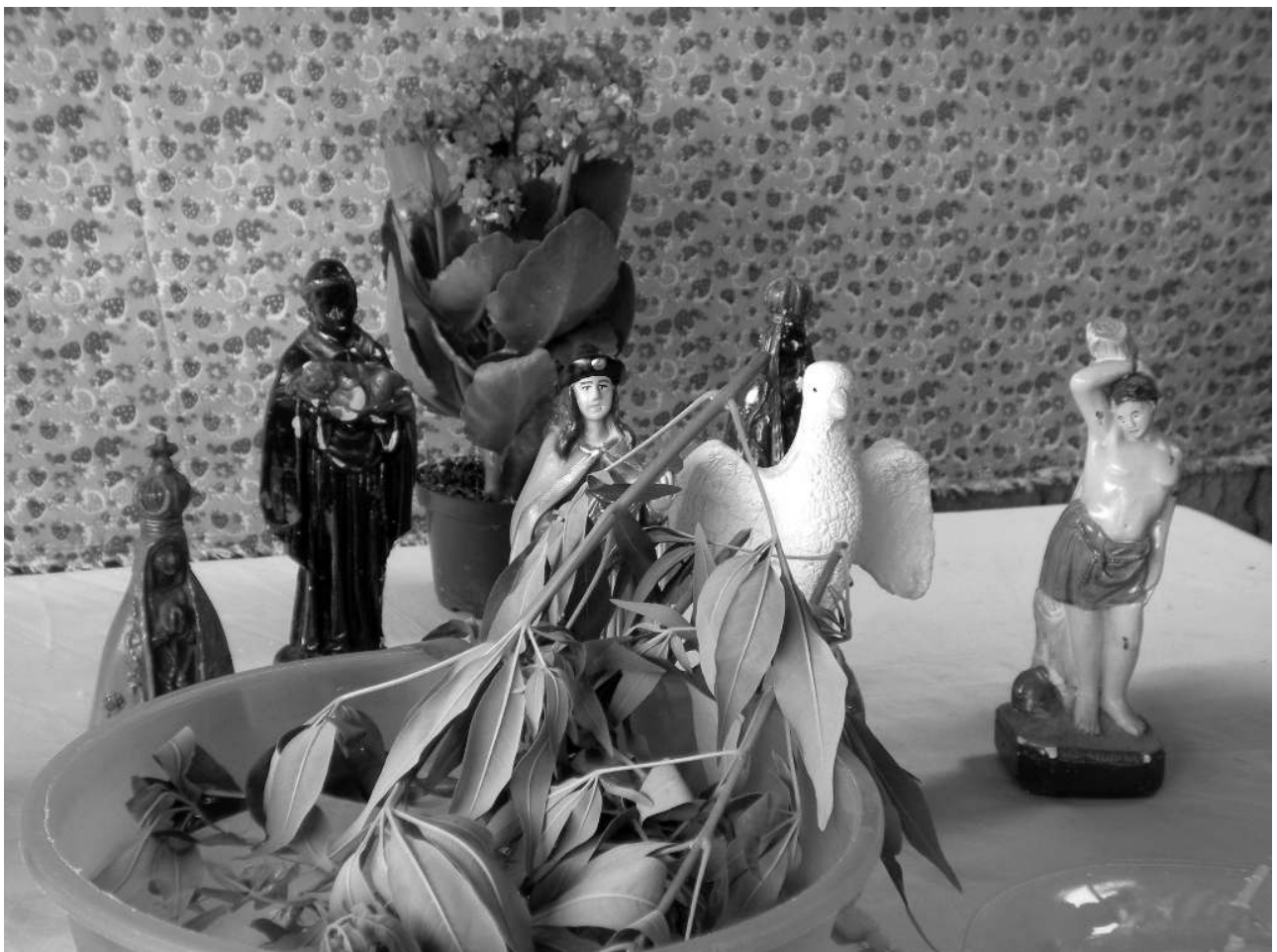

Figura 3 - Detalhe do altar, Cuiabá (MT). Foto: Patricia Osorio, 2012.

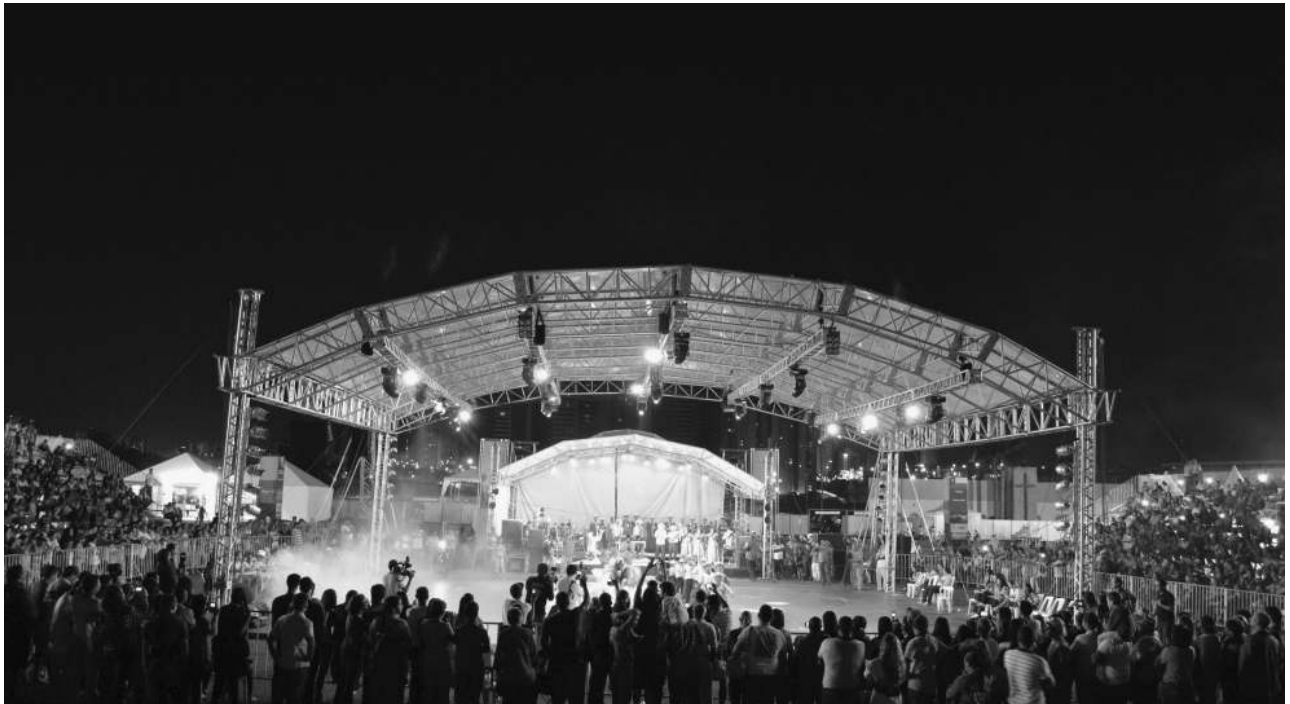

Figura 4 - Festival de Cururu e Siriri, Cuiabá (MT). Foto: Patricia Osorio, 2014. 
essencialmente por vizinhos e parentes dos dançarinos e tocadores que irão se apresentar na arena (figura 4 ).

O Festival de Cururu e Siriri não obedece a um calendário fixo associado a datas comemorativas de santos católicos. O momento de realização da festa está atrelado à disponibilidade de recursos financeiros advindos do poder público. Desde 2002 o Festival tem sido realizado anualmente, com exceção do ano de 2012, quando o evento foi cancelado por falta de financiamento. Para a realização da festa desenha-se uma relação de dependência entre o poder público local e lideranças dos grupos de siriri e cururu. O festival desencadeia relações paradoxais entre os representantes dos grupos de siriri e cururu e representantes da administração pública local: se, por um lado, as relações estabelecidas são de dependência do poder público para a realização da festa, o festival coloca-se como uma conquista dos grupos na luta por visibilidades e reconhecimentos.

Observa-se o vínculo entre patrimônios e festivais. Há um cruzamento entre tempos históricos: o tempo de emergência dos festivais de cultura popular e o tempo de emergência dos patrimônios imateriais no Brasil. Data da virada do novo milênio o Decreto N. ${ }^{\circ}$ 3551, de 04 de agosto de 2000, que instituiu o Registro de Bens Culturais de Natureza Imaterial e criou o Programa Nacional do Patrimônio Imaterial. O período de realização da primeira edição do festival coincide com a retomada das pesquisas sobre a viola de cocho pelo Centro Nacional de Folclore e Cultura Popular (CNFCP). ${ }^{3}$ Em 1988 é realizada no Rio de Janeiro, no CNFCP, uma exposição sobre a viola de cocho, o siriri e o cururu. A exposição foi construída a partir de uma pesquisa feita pela antropóloga Elizabeth Travassos e pelo músico Roberto Correa em alguns municípios do estado de Mato Grosso. Em 2003, no âmbito do Projeto Celebrações e Saberes da Cultura, a pesquisa é ampliada para outros municípios de Mato Grosso, utilizando a metodologia do "Inventário Nacional de Referências Culturais". As pesquisas foram subsídios importantes na formulação do dossiê de instrução que possibilitou a inscrição do "Modo de Fazer Viola de Cocho" no "Livro de Registro dos Saberes" do Instituto do Patrimônio Histórico e Artístico Nacional (IPHAN), conferindo-lhe o título de Patrimônio Cultural do Brasil em 14 de janeiro de 2005. ${ }^{4} \mathrm{O}$ título reconhece a viola de cocho e o complexo musical, coreográfico e poético que o instrumento integra, ou seja, o siriri e o cururu, como patrimônios imateriais brasileiros. No dossiê de instrução, produzido pelo CNFCP, a importância do registro e salvaguarda da viola de cocho como patrimônio imaterial está atrelada a possíveis ameaças à continuidade do saber

3 Sediado no Rio de Janeiro, o CNFCP é uma instituição pública destinada à pesquisa, documentação e difusão de formas expressivas das culturas populares brasileiras.

4 Mais informações em < http://portal.iphan.gov.br/pagina/detalhes/57 > (última consulta em outubro de 2017). 
registrado: idade avançada de seus executantes e um episódio associado à disputa judicial sobre o registro da marca "Viola de Cocho" junto ao Instituto Nacional de Propriedade Intelectual em benefício de um indivíduo (ver IPHAN 2009; Vianna 2005).

A conexão entre o festival e o emergente protagonismo que a viola de cocho assume, conferido entre outros elementos pelas políticas públicas associadas à valorização e salvaguarda dos patrimônios imateriais brasileiros, não é mecânica. Mas o vínculo é crucial para a reflexão sobre as formas expressivas populares patrimonializadas.

Ao alinharem os festivais a reflexões principalmente sobre o turismo, muitas análises chamam atenção para a importância de uma perspectiva analítica que abarque outras interações sociais, sistemas econômicos e redes comunicacionais para além dos eventos festivos. "Festivals, while containing worlds, also open out and spill over into 'outside' worlds and their multiple dimensions can only be understood by taking into consideration the different realities of the outside worlds" (Picard e Robinson 2009: 4). Tal perspectiva amplia o escopo da investigação, correspondendo aos desafios das etnografias contemporâneas sobre culturas populares. No entanto, parece haver algo nas análises que reforça a existência de um "mundo de dentro" e um "mundo de fora". Por mais que seja destacada a articulação entre mundos, há a construção da ideia da festa e de seu mundo próprio versus outros mundos. O que gostaria de sublinhar é que a ideia de festa, tomada em seu sentido antropológico como o lócus privilegiado para a materialização de identidades e da interação social, se faz presente tanto no cenário "tradicional", como no cenário dos grandes festivais. Os processos de patrimonialização, o mercado e o turismo são constituintes da festa, fazendo parte do cotidiano dos grupos de cultura popular. Os "mundos de fora" estão dentro da festa. Adotar esta perspectiva analítica não corresponde à negação da existência de conflitos e poderes desiguais reproduzidos e engendrados no evento festivo. Os festivais são campos de batalhas constituídos por interações sociais alicerçadas em redes de parentesco e vizinhança, na ideia de tradição, mas também pelo entretenimento, pela mídia, pelo turismo, pelas políticas patrimoniais e pelas esferas administrativas e políticas locais. $\mathrm{E}$ as batalhas travadas se dão por meio de um complexo jogo performático construído e encenado por diferentes agentes: representantes da política local, lideranças dos grupos, dançarinos e tocadores de cururu e siriri.

\section{TEXTUALIZAÇÕES NA DANÇA E NA NÃO DANÇA}

Ao perseguir os modos como as performances estão enquadradas no Festival de Cururu e Siriri, é possível classificá-las em dois tipos: performances da não dança, com ênfase na dimensão comunicativa dos discursos/palavra, e performances centradas no potencial comunicativo da dança. A categorização não 
pretende estabelecer uma divisão inequívoca entre a palavra e o movimento. A articulação entre o movimento e a palavra é fundamental para o entendimento das performances festivas. Se, analiticamente, não é possível separar a palavra do movimento, uma vez que a palavra, o corpo e a dança estão na festa, há claramente uma organização no "ritmo" do espetáculo que demarca fronteiras entre a dança e a não dança.

As performances da não dança correspondem ao momento inicial do festival e caracterizam-se pelos discursos autorizados de políticos e lideranças dos grupos de cururu e siriri. É na abertura do evento que o palco é ocupado pelas autoridades presentes. Os enunciados emitidos envolvem tensões que se dão em dois planos: partidárias e em torno da tradição.

As disputas partidárias tomam forma na oposição entre as esferas estadual e municipal do poder público local. Políticos ocupam o palco e marcam suas posições. As lideranças dos grupos reforçam a disputa ao destacarem o apoio de uma das esferas em detrimento da outra. O público também participa desses momentos, ora com aplausos, ora com vaias, manifestando aprovações e reprovações. Demarcações partidárias são feitas e zonas discursivas conflitantes se instauram.

Durante a realização do trabalho de campo, pude perceber que a oposição entre os poderes estadual e municipal reverbera nas disputas em torno dos possíveis precursores e inventores do festival. Seja nos discursos dos políticos ou das lideranças dos grupos, o evento aparece como sendo, a princípio, uma iniciativa de políticos locais em prol da "cultura popular mato-grossense" e em defesa da "tradição". A festa torna-se uma arena na qual políticos rivais duelam e poderes são manipulados a partir do uso da tradição. Nos discursos autorizados, a festa coloca-se como o lugar por excelência da legitimação de uma enunciação sobre a tradição que endossa a construção da identidade regional. O festival afirma-se como a "festa máxima do folclore estadual"; "expressão das gentes de Mato Grosso"; a "maior e mais tradicional festa da cultura popular de Mato Grosso". As funções da festa também são enunciadas: "ajudar a manter a cultura"; "preservar as tradições"; "divulgar e promover a cultura mato-grossense"; "revitalizar e conservar as origens"; além de "movimentar a economia gerando emprego e renda". O festival aparece nas falas oficiais como parte do "calendário cultural" da cidade e da região. A ideia de tradição é reivindicada ao lado do processo de criação da coletividade, do povo mato-grossense, e da construção "oficialesca" da identidade regional.

É central o papel que a cultura popular desempenha desde o século XIX na formulação de identidades locais, regionais e nacionais (Leal 2007: 81). ${ }^{5} \mathrm{Em}$ Mato Grosso, a apropriação de expressões e saberes considerados folclóricos 
como um componente importante do processo de construção identitária regional é extremamente recente. O cururu e o siriri, até final dos anos 80, eram vistos de forma depreciativa e associados às imagens de "preto", "pobre" e "matuto". ${ }^{6}$ Por muito tempo invisíveis nas mídias locais, as manifestações passaram entretanto a ocupar um espaço significativo nos veículos midiáticos, e essa visibilidade do cururu e siriri está estreitamente relacionada à valorização dada pelas políticas patrimoniais. Podemos dizer que o caso etnográfico aqui tratado é um bom exemplo de como no século XXI as políticas voltadas aos patrimônios culturais colocam-se como geradoras dos movimentos identitários.

Os discursos de afirmação da identidade regional via tradição intensificaram-se durante os anos de 2013 e 2014. Cuiabá foi uma das cidades-sede para os jogos da Copa do Mundo, realizados no Brasil em 2014. As expectativas em torno da exibição do siriri e cururu durante o megaevento foram inúmeras. Uma delas dizia respeito à remodelação do espaço em que o festival vinha sendo realizado e, consequentemente, à construção de um lugar definitivo para a tradição, a Arena do Cururu e do Siriri. Nos discursos dos políticos, o festival transformou-se em uma promessa; nos discursos dos representantes dos grupos, em um sonho.

Os desdobramentos das expectativas em torno da construção de um lugar próprio para a exibição da tradição configuraram-se na desterritorialização do festival. Analisando cronologicamente as várias edições, é possível identificar algumas tendências que sublinham a importância do lugar de realização do festival para os grupos de siriri e cururu. Importante destacar que os grupos de siriri e cururu estão localizados em bairros periféricos de Cuiabá ou em áreas rurais de pequenas cidades localizadas no interior do estado. A escolha do local para o festival expõe importâncias simbólicas. As edições do festival têm sido realizadas nas imediações de um bairro de grande representatividade histórica para a cidade. O festival é o tempo e o espaço em que o cururu e o siriri ocupam o "centro" da cidade.

Durante a Copa do Mundo, o festival foi deslocado e o palco dos festivais transformou-se na FIFA Fan Fest. ${ }^{7}$ Paralelamente à programação organizada pela FIFA, foi improvisado o festival em um outro espaço mais distante do centro, a Arena Cultural. As programações da Arena Cultural e da FIFA Fan Fest eram concomitantes. O cururu e siriri disputaram público com os shows de bandas nacionais de axé, forró, sertanejo e samba.

6 São vários os relatos dos brincantes mais velhos que denunciam preconceitos associados à prática do cururu e do siriri.

7 Organizado pela Federação Internacional de Futebol, o FIFA Fan Fest constituiu-se em um espaço improvisado em grandes áreas de todas as cidades sedes brasileiras e foi dedicado a stands de propagandas, restaurantes, bares e grandes shows musicais. 
$\mathrm{Na}$ construção dos enunciados de afirmação da identidade regional, o lugar da tradição assume um papel importante. São corriqueiras frases emitidas pelos representantes do poder público local como as seguintes: "A cultura de Mato Grosso é vivida na Arena"; ou "Essa festa marca a nossa história, nós temos o cururu, siriri que passarão por esta arena". A legitimação e a definição do que é a cultura mato-grossense estão estreitamente imbricadas ao lugar de exibição da "cultura imaginada". Se o lugar da cultura é utilizado por políticos locais no processo de construção e afirmação de uma identidade regional, o lugar transforma-se na materialidade da luta política dos grupos pela visibilidade e positividade de expressões culturais entendidas como tradição.

Diana Taylor (2013), em uma reflexão sobre protestos de rua no México, com o intuito de ilustrar o grau em que as estruturas e hierarquias políticas tradicionais são contestadas, elabora uma distinção entre dois tipos de elementos da performance: os performativos políticos e os animativos. Amparada em Austin, a autora entende os performativos como as performances verbais, cercadas por convenções e códigos, executadas por atores sociais autorizados, enquanto que os animativos se baseiam em corpos e ocorrem em interações caóticas e menos codificadas. O animativo é o tumulto; o performativo, as declarações autorizadas e oficialescas. "Os animativos aterrorizam os governos, cujo objetivo principal é o controle dos corpos através do uso de ordens, enunciados oficiais e decretos performativos como força legal" (2013: 219). Resguardando as especificidades dos cenários etnográficos, é possível afirmar que o performativo e o animativo se cruzam no festival.

No festival, os performativos políticos se fazem presentes nos momentos da não dança. É na não dança que são encenados os discursos autorizados da tradição como canais privilegiados para reforçar as ideias de coesão e homogeneidade da identidade regional. No entanto, é também nestes momentos que os "animativos" interferem nos "performativos", quando representantes dos grupos desconstroem os discursos autorizados dos políticos fazendo cobranças e expondo reivindicações. Aqui, os discursos mais homogêneos tornam-se heterogêneos e as performances verbais utilizadas na construção da identidade regional cedem espaço para performances verbais (e extremamente emocionais) voltadas para questões direcionadas à cidadania, tornando públicas as reivindicações locais. E se pensamos os animativos como aquelas performances dinamizadas nas expressões que se passam no palco do festival, quando entram em cena e movimento os dançarinos e músicos, em que as performances verbais cedem o protagonismo para o corpo, a dança e a música, percebemos mais uma vez a mistura entre os dois elementos da performance. A dança no palco, ao mesmo tempo em que pode trazer a dimensão do tumulto e uma contratextualização em relação aos discursos autorizados sobre identidades, traz também o controle e o reforço das textualizações já anunciadas. É importante, assim, analisar o lugar e as funções assumidos no espetáculo pela viola 
de cocho, pensada aqui como a materialização de um modo de fazer transformado em patrimônio imaterial.

As performances da dança iniciam-se com a apresentação de um grupo de cururu. Homens, em sua maioria mais velhos, dispõem-se no centro do palco, em roda. Durante toda a apresentação, as mãos estão ocupadas segurando a viola de cocho ou o ganzá. A dança não traz elementos expansivos e não é utilizado nenhum recurso cênico ou alegoria, com exceção da própria viola de cocho.

Se há uma única apresentação de cururu por noite, cerca de oito grupos de siriri ocupam a arena do festival diariamente. Embora as apresentações dos grupos de siriri apresentem particularidades, há vários elementos em comum. Elas se iniciam com uma abertura. $\mathrm{O}$ momento contém forte apelo religioso. Imagens de santos são trazidas ao palco, seja em esculturas de gesso e madeira, gravuras, bandeiras, cartazes, ou mesmo mimetizadas em atores que se vestem de santos católicos. As canções também tocam na dimensão religiosa (figura 5).

A passagem deste momento, chamado de louvor, para a dança de siriri é marcada pela mudança no andamento melódico. Dançarinos e dançarinas ocupam o centro do palco executando complexos desenhos coreográficos. Em uma das laterais do palco posicionam-se os tocadores de viola de cocho, mocho e ganzá, assim como o coro formado por vozes masculinas e femininas. Recursos cênicos cada vez mais têm sido usados nas apresentações, evocando o modo de vida ribeirinho. Entre jangadas, redes de pesca e potes de cerâmica, destaca-se a viola de cocho.

Em folhetos de divulgação, estampada nas saias das dançarinas, decorando o cenário, a viola de cocho transforma-se no patrimônio a ser mostrado. Sua função no festival é a de exibir o patrimônio. Esta função fica latente, por exemplo, se observamos as apresentações dos grupos de cururu. O som das violas de cocho e dos versos de improviso que chega ao público não advém da performance exibida no cen-

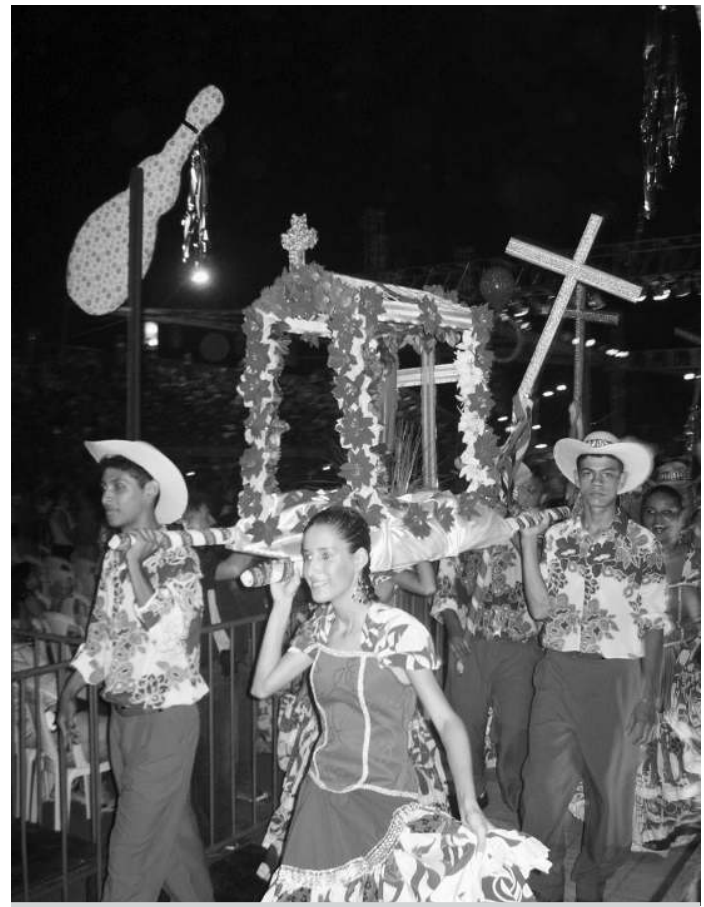

Figura 5 - Momento inicial das apresentações dos grupos de siriri, Festival de Cururu e Siriri, Cuiabá (MT). Foto: Patricia Osorio, 2009. 


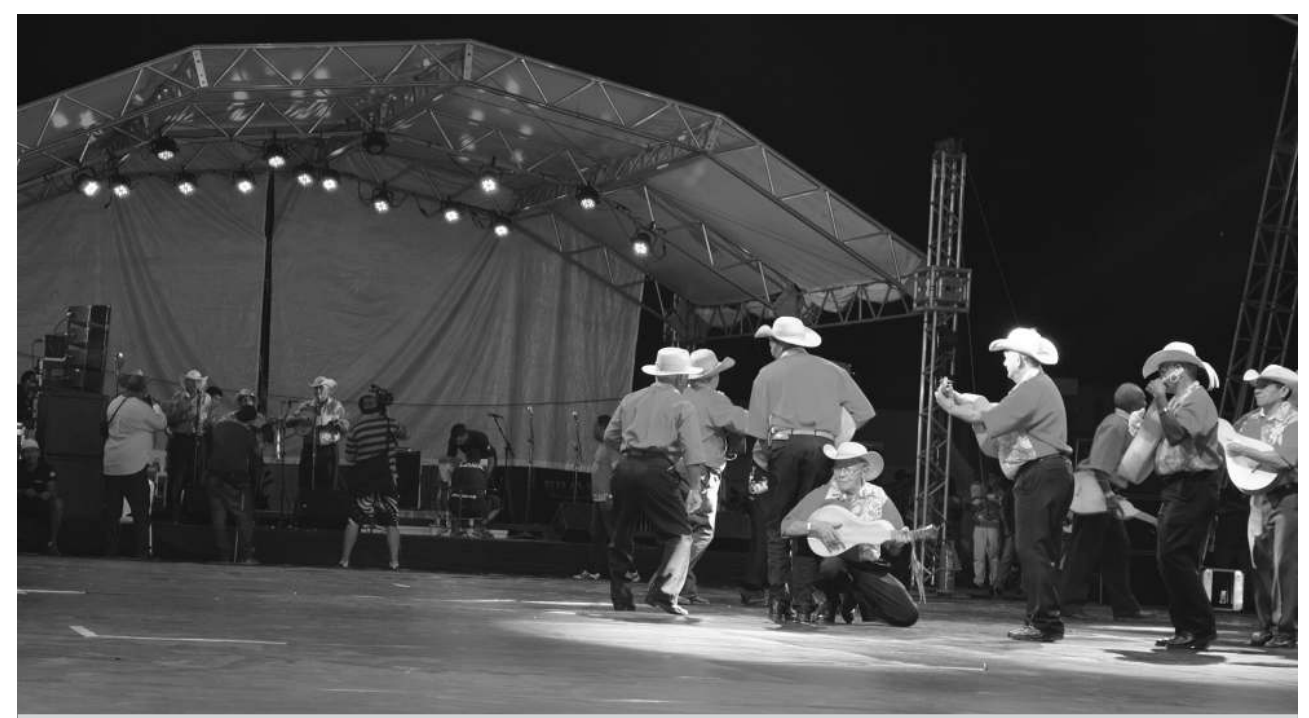

Figura 6 - Festival de Cururu e Siriri, Cuiabá (MT). Foto: Patricia Osorio, 2014.

tro do palco. Acopladas a microfones, as violas de cocho são manejadas fora do palco e do campo de visão do público. A música não é "vista" pelo público, uma vez que os cururueiros estão posicionados em um espaço periférico e pouco iluminado da arena. Cria-se no espetáculo unidades separadas entre a execução musical e a dança. Os cururueiros que tocam não dançam, os que dançam não tocam. O festival separa a dança da música. E, entre a dança e a música, a primeira assume o protagonismo no evento festivo (figura 6).

A viola de cocho revela uma segunda vida (Kirshenblatt-Gimblett 1998). A segunda vida dos patrimônios emerge quando objetos e pessoas são fabricados para performar seus significados para os outros. Os significados da viola de cocho no festival surgem na própria exposição do objeto patrimonializado. No festival, o patrimônio assume a posição de representação teatral.

Patrimônios possuem ressonâncias, evocam nos espectadores forças culturais de onde emergiram (Gonçalves 2007: 215). E se os festivais são locais de exibição dos patrimônios, são também lugares geradores de excessos de ressonâncias. Na dança e não dança, o patrimônio legitima identidades nacionais e regionais, da mesma forma que é apropriado pelos grupos para reforçar redes de reciprocidade baseadas em relações de parentesco e vizinhança. Destinado a sustentar patrimônios, o festival é o lócus propício para produzir patrimônios com excessos de ressonância que se cruzam nas narrativas performáticas da festa.

Os festivais são mostruários da apresentação do patrimônio imaterial, um exemplo de como colocar a política patrimonial em prática (Kirshenblatt-Gimblett 2004). As intervenções patrimoniais mudam as relações com as 
pessoas e com o que elas fazem, e mudam as condições fundamentais para a produção e reprodução cultural (2004: 58). Sendo a mudança intrínseca à cultura, medidas destinadas a preservar, conservar, salvaguardar e sustentar práticas culturais particulares estão aprisionadas entre o congelamento da prática e o tratamento da natureza inerentemente processual da cultura (2004: 58-59). Nesse sentido, a noção de performance parece ser útil para problematizarmos as tensões entre as formas e saberes expressivos populares e as políticas patrimoniais.

\section{PERFORMANCES, PATRIMÔNIOS E POLÍTICAS DE IDENTIDADES}

Tomo de empréstimo a metáfora bélica utilizada por David Guss (2000b) para refletir sobre as festas, e podemos estendê-la aos patrimônios. As festas e os patrimônios constituem-se em campos de batalha em que diferentes grupos pleiteiam interesses identitários. Ao associar patrimônio imaterial e identidade, o intuito é o de pensar os processos de patrimonialização do imaterial como contextos geradores de ações políticas nas quais múltiplas identidades são construídas, rejeitadas e disputadas. O Festival de Cururu e Siriri é um caso privilegiado para refletirmos sobre tais dinâmicas. Não apenas o festival estabelece um alto padrão para a apresentação do patrimônio - em que os grupos submetem-se a ensaios rigorosos, empreendendo uma série de adaptações no formato das coreografias e indumentárias -, mas também propicia uma teatralização. A viola de cocho assume o protagonismo, ganhando novas funções, tornando-se uma espécie de metacultura, conforme já foi exemplificado anteriormente.

É dentro desse contexto que identidades são performadas. A noção de performance é promissora para pensarmos as relações entre formas e saberes expressivos populares e políticas de patrimônios em dois sentidos. O primeiro deles é aquele que sublinha o poder performativo dos patrimônios. Este caminho de análise assume o patrimônio como performance: uma performance em que certos significados culturais e sociais e valores são identificados, reafirmados ou rejeitados. Patrimônio pode ser uma forma de controle social, ou, ao menos, de negociação sobre valores sociais e significados (Smith 2011 : 69-70). Assim, o patrimônio é utilizado para legitimar reivindicações identitárias e deslegitimar outras. Todo o patrimônio é dissonante e controverso: pode ser inclusivo e confortável para um grupo, excludente e desconfortável para outro. Ele é contestado e disputado. O festival é um momento dedicado à construção de uma identidade regional mais alargada e oficial, ao mesmo tempo em que são afirmados e celebrados vínculos mais específicos, como as redes de parentesco, amizade e de vizinhança. Outras reivindicações também se fazem presentes, como a de visibilidade por parte de grupos das periferias urbanas e rurais. Ideias sobre etnicidade também estão sendo negociadas. Alguns grupos 
de siriri trazem para o palco encenações históricas que demarcam o momento de encontro e desencontro entre portugueses e indígenas. Observa-se também no festival a apresentação de grupos de siriri advindos de comunidades quilombolas da região, que nos movimentos da dança, na composição das vestimentas, nas canções e na utilização de outros instrumentos musicais, como o atabaque, expõem sinais diacríticos que ressaltam a afirmação de um grupo étnico em específico. No entanto, a visibilidade no contexto dos grandes espetáculos acarreta uma série de alterações nas formas expressivas populares, agora transformadas em patrimônios exibidos nos festivais. Se a transformação de saberes e expressões em patrimônios transforma as relações entre pessoas e suas experiências com seus saberes e expressões, ela desencadeia igualmente uma série de desafios relativos aos modos como os bens culturais (que são também sociabilidades alicerçadas em redes de parentesco, vizinhança, religiosidades e formas específicas de divertimento) são vivenciados. O festival constitui-se em um campo de batalha em que sociabilidades festivas específicas misturam-se ao entretenimento, à mídia, ao turismo, às políticas patrimoniais, às esferas administrativas e políticas locais e regionais.

O segundo sentido no qual podemos pensar performance e patrimônio é o de sublinhar um certo antagonismo entre as duas noções. Seja nos manuais, em cartas, nos decretos, nas recomendações formuladas por organismos nacionais ou internacionais, a noção de patrimônio está associada à noção de preservação. O reconhecimento oficial é o de que os patrimônios constituem-se em heranças consideradas significativas e por isso devem ser transmitidos para as gerações futuras, de modo que seja assegurada sua duração no tempo e no espaço. Nos dicionários da língua portuguesa, patrimônio relaciona-se com defender, resguardar, conservar, blindar, imunizar. Importante sublinhar que há um antagonismo entre esta concepção, que se reflete nas políticas patrimoniais, e os "patrimônios na prática". Há um descompasso entre os patrimônios e suas performances. E, mesmo identificando tal descompasso e por mais paradoxal que possa parecer, é justamente no momento das performances que os patrimônios são atualizados. Tocar, dançar ou exibir a viola de cocho no festival colocam-se como possíveis atos de criação de agências com as quais identidades são reforçadas, chanceladas, renunciadas e negociadas. ${ }^{8}$

A ambivalência é inerente aos processos identitários. Clifford (2000) destaca a inseparabilidade entre empoderamento local e chauvinismo, comunidade e exclusão, performance e mercantilização, posicionamento e governabilidade. Identidades podem ser a base para a conexão e para a desconexão (2000: 106). Essa é a ambivalência das identidades, das festas, e também dos patrimônios.

8 Estudos sobre a dança têm sublinhado a percepção da estética do movimento como geradora de ação política (Quintero 2011; Lepecki 2013). 


\section{BIBLIOGRAFIA}

BOISSEVAIN, Jeremy, 1992, Revitalizing European Rituals. Londres, Routledge.

CAVAlCANTI, Maria Laura Viveiros de Castro, 1994, Carnaval Carioca: Dos Bastidores ao Desfile. Rio de Janeiro, Funarte, UFRJ.

CLIFFORD, James, 2000, "Taking identity politics seriously: 'The contradictory, stony ground...'”, em Paul Gilroy e Lawrence McRobbie (orgs.), Without Guarantees: Essays in Honour of Stuart Hall. Londres, Verso, 94-1 12.

DURKHEIM, Emile, 1996 [1912-13], As Formas Elementares da Vida Religiosa: O Sistema Totêmico na Austrália. São Paulo, Martins Fontes.

GEERTZ, Clifford, 1989, Interpretação das Culturas. Rio de Janeiro, Guanabara.

GONÇALVES, José Reginaldo, 2007, Antropologia dos Objetos: Coleções, Museus e Patrimônios. Rio de Janeiro, Garamond.

GUSS, David, 2000a, The Festive State: Race, Ethnicity, and Nationalism as Cultural Performance. Berkeley, Los Angeles, Londres, University of California Press.

GUSS, David, 2000b, "Moros y cristianos y mujeres e índios: Tamunangue y las fronteras de la etnicidad", Revista de Investigaciones Folclóricas, 15: 9-14.

GUTIÉRREZ, Ramón A., e Geneviève FABRE (orgs.), 1995, Feasts and Celebrations in North American Ethnic Communities. Albuquerque, University of New Mexico Press.

IBGE - Instituto Brasileiro de Geografia e Estatística, 2012, Mapas Estaduais. Rio de Janeiro, IBGE, disponível em < https://7al2.ibge.gov.br/images/7a12/estados//mato_grosso.pdf > (última consulta em outubro de 2017).

IBGE - Instituto Brasileiro de Geografia e Estatística, 2017, Área Territorial Brasileira. Rio de Janeiro, IBGE.

IPHAN - Instituto do Patrimônio Histórico e Artístico Nacional, 2009, Modo de Fazer a Viola de Cocho. Brasília, IPHAN.

KIRSHEnBlatT-GIMBLETT, Barbara, 1998, Destination Culture: Tourism, Museums and Heritage. Berkeley, Los Angeles, University of California Press.

KIRSHENBLATT-GIMBLETT, Barbara, 2004, "Intangible heritage as metacultural production”, Museum Internacional, 56 (1-2): 52-65.

LEAL, João, 1994, As Festas do Divino Espírito Santo nos Açores: Um Estudo de Antropologia Social. Lisboa, Publicações Dom Quixote.

LEAL, João, 2007, Cultura e Identidade Açoriana: O Movimento Açorianista em Santa Catarina. Florianópolis, Insular.

LEPECKI, André, 2013, "Planos de composição: dança, política e movimento", em Paulo Raposo et al. (orgs.), A Terra do Não-Lugar: Diálogos entre Antropologia e Performance. Florianópolis, Editora da Universidade Federal de Santa Catarina (EdUFSC), 109-120.

OLIVEn, Ruben G., 1992, A Parte e o Todo: A Diversidade Cultural no Brasil-Nação. Petrópolis, Vozes.

PICARD, David, 2016, "The festive frame: festivals as mediators for social change", Ethnos, 81: 600-616.

PICARD, David, e Mike ROBINSON (orgs.), 2009, Festivals, Tourism and Social Changes: Remaking Worlds. Clevedon, Bufalo, Toronto, Channel View Publications.

QUINTERO, Juan Felipe C., 2011 , "Las políticas de las coreografias en el Festival Mundial de Salsa de Cali”, em Maria Julia Carozzi (org.), Las Palavras y los Passos: Etnografias de la Danza en la Ciudad. Buenos Aires, Gorla, 155-188. 
RAPOSO, Paulo, 2010, Por Detrás da Máscara: Ensaio de Antropologia da Performance sobre os Caretos de Podence. Lisboa, Ministério da Cultura, Instituto dos Museus e da Conservação.

SMITH, Laurajane, 2011 , "The doing of heritage: heritage as performance", em Anthony Jackson e Jenny Kidd (orgs.), Performing Heritage: Research, Practice and Innovation in Museum Theatre and Live Interpretation. Manchester, Manchester University Press, 69-81. TAYLOR, Diana, 2013, "Cidadania em performance: os artistas vão às ruas", em Paulo Raposo et al. (orgs.), A Terra do Não-Lugar: Diálogos entre Antropologia e Performance. Florianópolis, Editora da Universidade Federal de Santa Catarina (EdUFSC), 21 1-222.

TRAVASSOS, Elizabeth, 1997, Os Mandarins Milagrosos: Arte e Etnografia em Mário de Andrade e Béla Bartók. Rio de Janeiro, Zahar.

TURNER, Victor, 2013, O Processo Ritual: Estrutura e Antiestrutura. Petrópolis, Vozes.

VELASCO, Honorio (org.), 1982, Tiempo de Fiesta. Madrid, Tres-Catorce-Diecisiete.

VIANNA, Letícia, 2005, "O caso do registro da viola de cocho como patrimônio imaterial", Sociedade e Cultura, 8 (2): 53-62.

VILHENA, Luis Rodolfo, 1995, Projeto e Missão: O Movimento Folclórico Brasileiro. Rio de Janeiro, Funarte, Fundação Getulio Vargas. 